\title{
REFLEXÕES SOBRE A TERRITORIALIZAÇÃO DA POBREZA EM CIDADES BRASILEIRAS
}

\section{REFLECTIONS ON THE TERRITORIALIZATION OF THE POVERTY IN BRAZILIAN CITIES}

\author{
Elias Coimbra Da Silva ${ }^{1}$ \\ Universidade Federal de Uberlândia, Brasil
}

http://dx.doi.org/10.15359/rgac.3-59.1

\begin{abstract}
RESUMO
O texto que ora apresentamos é uma tentativa de problematizar a reprodução de certos lugares à margem da produção capitalista do espaço, bem como as territorialidades envolvidas nesse processo. Lugares esses de pobreza, de exclusão, de vulnerabilidade e que requerem dos geógrafos um olhar diferenciado. Para realizar esse intento, consideraremos algumas propostas de análise de cidades médias paulistas nas quais as ocupações irregulares fizeram-se presentes, além de teorias reconhecidas que tratam da questão da pobreza. Ao mesmo tempo, queremos propor outro modo de entender o conceito de território, as relações de poder que o permeiam e as suas redes de reciprocidades, partindo da análise, específica, da Favela da Avenida Rio Pardo, na cidade brasileira de Ribeirão Preto. Esperamos assim, contribuir na compreensão das desigualdades sociais, inclusive no nível espacial, bem como para pensar o advento de novos atores e de novos processos de territorialização.
\end{abstract}

Palavras-chave: Território Marginal, Poder, Favela, Rede.

1 Doutor em história e doutorando em geografia pela Universidade Federal de Uberlândia, Minas Gerais, Brasil, trabalha como professor no ensino básico. Correio eletrônico: <coimbraelias@hotmail.com>

Fecha de recepción: 23 de enero de 2017

Fecha de aceptación: 26 de abril de 2017 
Elias Coimbra Da Silva. Reflections on the territorialization of the poverty in brazilian cities

\begin{abstract}
This text aims at questioning the reproduction of certain places outside the capitalist production of space, as well as the territorialities involved in this process. Places of poverty, exclusion and vulnerability which require a different perspective from geographers. In order to update this attempt, we will consider some analysis proposals on the medium-sized cities of São Paulo in which irregular settlements are present, in addition to important theories on the issue of poverty. At the same time, we will propose another way of understanding the concept of territory, the power relationships that permeate it as well as its exchange networks, starting from a specific analysis of Avenida Rio Pardo slum in the Brazilian city Ribeirão Preto. Thus, we expect to contribute to the understanding of social inequalities even at spatial level, as well as to think about the advent of new actors and new processes of territorialization.
\end{abstract}

Keywords: Marginal Territory, Power, Slum, Network.

\title{
Introdução
}

Num texto já clássico, na historiografia, onde faz alusão às agruras da vida dos escravos negros, Portelli cita um acontecimento muito curioso. Segundo esse mesmo historiador, num tribunal, instado a dizer a verdade, somente e nada mais do que a verdade, a testemunha (um indígena norte-americano) teria respondido que poderia dizer somente o que ele sabia. ${ }^{2}$

Essa alegoria pode nos conduzir à reflexão - mais óbvia - acerca da história como ponto de vista, mais do que como "realidade nua e crua". Em jornalismo, tal circunstância é tida como um dos seus princípios básicos - aquilo que eles (os jornalistas) costumam denominar de "império dos fatos" (Cosson, 2005, p. 57). Além disso, a mesma alegoria pode igualmente nos conduzir a pensarmos na complexidade do próprio processo histórico ${ }^{3}$; e esse é o ponto o qual queremos destacar.

Dentro das cidades - com suas máquinas de morar ${ }^{4}$ - as pessoas organizam-se, dando assim forma e conteúdo aos seus modos de vida. Ao mesmo tempo e numa outra Escala, o gestor público - motivado ou não por interesses coletivos - organiza o espaço urbano segundo parâmetros técnicos, econômicos etc., parâmetros esses que não coincidem com as

2 “[...] o antropólogo James Clifford conta, na introdução de seu Writing Culture, a história do índio canadense Cree que foi chamado a prestar um depoimento perante um tribunal; quando the foi pedido que jurasse dizer toda a verdade, a testemunha respondeu: Não sei se posso dizer a verdade... posso apenas dizer o que sei". (Portelli, 1996, p. 63)

3 Espero que a inclusão desta nota não pareça pedantismo meu. O caso é que estou já tão habituado com alguns termos da pesquisa histórica que, eventualmente, posso até subestimar a importância dos mesmos; "processo histórico" é um bom exemplo. Com esse termo, os historiadores distinguem um certo "aquilo que aconteceu de fato" - que é inescrutável - de uma outra coisa que seria a narrativa sobre os fatos.

4 "Defende, Le Corbusier, que a casa deve ser uma máquina de morar, com economia e eficiência industriais." (Cavalcanti, 2006, p. 43) 
necessidades específicas dos grupos (para evitar dizer, neste ponto, classes); quando não, até mesmo, as contrariam. Tal é a complexidade do processo histórico - conforme a utilização que propomos, desse conceito.

Da mesma forma, sobrepõe-se a essa complexidade - questão de fato que é - uma outra ordem de questões. Ordem outra que nos remete, diretamente, às maneiras de existir dos grupos humanos que acrescentam, ao grande puzzle social (ou melhor, a Sociedade tout court), sua pequena peça. Com esse termo ("peça") referimo-nos, para sermos mais explícitos, à construção daquelas autoimagens que costuma-se denominar de: Identidade Social ${ }^{5}$.

Complexidade do processo, ou seja, dos fatos, e complexidade das identidades no interior de um único corpo: uma cidade. O que propomos em nossa pesquisa - ante a qual o presente texto constitui-se num work-in-progress - é uma tentativa de explicar como e por que esse fenômeno que denominaremos de "território marginal", é constituído e à margem (ou à revelia) da ação do Estado. Estado esse, presente tanto como o ente administrativo, como enquanto aquela parcela não-privada do espaço urbano e da sociedade; mas que deve dividir com outros atores a tarefa da produção desse mesmo espaço. A propósito, não é muito distinta a ideia sugerida por Raquel Rolnik, quando diz que a lei "determina apenas a menor parte do espaço construído" (1997, p. 13).

Esperamos, desta forma, contribuir para a compreensão das desigualdades sócio-espaciais, bem como para pensar o advento de novos atores nos processos de territorialização e de produção do espaço urbano. Atores, sujeitos, agentes, de uma cidade que acontece apesar do planejamento e que, não raras vezes, é estigmatizada ou mesmo destruída, em benefício da chamada Hegemonia. Mas, atores esses (homens, mulheres), nem sempre considerados na Geografia, dita humana, senão enquanto vítimas (objetos?) dos processos de exclusão.

Contrários a essa vitimização, pensamos que: “A exclusão social e a segregação espacial aparecem como formas simétricas e complementares na construção de grupos diferenciados e conscientes de suas especificidades" (Claval, 2013, p. 99). O que não implica dizer que os trunfos estão democraticamente distribuídos entre os atores dominantes, os atores

5 Utilizamos esse conceito, pautados naquela acepção de Claval expressa na afirmação: "As pessoas que vivem em uma política têm que dar um sentido a suas vidas" ou na ideia de "ambientes de memória". (Claval, 2013, p. 81) 
emergentes e atores os residuais - essa terminologia gramsciana emprestada em Raymond Williams (2000, p. 144) -, mas sim que os grupos segregados são mais do que aquelas vítimas das circunstâncias que, segundo Gottdiener (1993, p.80), pesquisadores como David Gordon, John Mollenkopf e Katznelson procuravam apresentar ${ }^{6}$.

No que tange ao nosso aporte de caráter teórico, também objeto de nossa investigação, buscamos problematizar, sobretudo, dois conceitos, ou noções. Primeiramente, cito a Territorialização. Estamos cientes da crescente luz lançada sobre ele nos estudos geográficos - o texto "Mito da Desterritorialização" de Rogerio Haesbaert (2006) é, nesse sentido, esclarecedor. A propósito, na obra dos franceses Deleuze e Guattari: "Mil Platôs" (1995/a/b), citados pelo próprio Haesbaert, é patente a presença desse mesmo conceito. Deste texto, ou melhor, conjunto de textos (e de Platôs), depreendem-se diversos outros conceitos seminais, como Agenciamento e Rizoma, tanto quanto o próprio método erigido o qual ainda não recebeu o devido reconhecimento entre os estudiosos do homem e da sociedade.

Por outro lado, cito a noção (conceito?) de "desigualdade", frente a qual encontramos o amplo problema que concerne também à exclusão/ inclusão social e todos os desdobramentos dessa dicotomia. Nesse caso, estamos familiarizados com as dificuldades de sua delimitação (ou definição), bem como com as soluções propostas; além de cônscios tanto das "formas institucionais da pobreza" , de Serge Paugan (apud Melazzo, 2006, p. 53), quanto do processo de "desfiliação" de Robert Castel (ibidem) e, portanto, somos conhecedores do trabalho de compreensão das "formas e processos sociais" - no sentido em que são explicadas(os) mais que explicitadas(os): "[...] Statistics on the overt behaviour of populations do not readily supply a test of the explanation" (Barth, 1981, p. 16) ${ }^{8}$.

\section{Referencial teórico}

Entre os autores que julgamos importantes para o recorte temático em questão, citamos Everaldo Melazzo (2006). A riquíssima fonte

6 Quanto a Gordon, nos referimos ao seu livro Capitalism and the roots of the urban crisis; em Mollenkopf, a referência é o livro The postwar politics of urban development; e em Katznelson, a referência é The crisis of the capitalist city.

7 É impossível não notar a íntima relação entre essa concepção pragmática da pobreza e a sociologia antiidealista de Bourdieu (1998).

8 Estatísticas sobre o comportamento manifesto das populações não suprem de maneira adequada ao teste da explicação. (tradução nossa) 
secundária, outorgada em sua avaliação prognóstica acerca de algumas cidades médias paulistas, nos autoriza a realizar diversas analogias.

Paralelamente, os já citados Serge Paugan e Robert Castel, junto de autores como André Campos fornecem importantes subsídios para pensarmos a Marginalização, a Pobreza, a Exclusão etc. Nesse sentido, destacamos que a pobreza, não pode continuar sendo compreendida com as chaves interpretativas tradicionais, sobretudo porque ser pobre hoje é diferente de ser pobre no período histórico pré-industrial: uma questão moral, a "degradação" (Paugan, 2003, p. 24), sobrepõe-se à questão econômica. Ademais, o empobrecimento - a desqualificação social, na terminologia de Paugan - não é uma ruptura instantânea em relação a uma determinada situação oposta, mas daria-se em pelos menos três estágios, não necessariamente cumulativos: a "fragilidade", a "assistência" e a "marginalidade" (Paugan, 2003).

Por outro lado, em nosso recorte nos deparamos com questões que se sobrepõem a esse circuito "estado $\leftrightarrow$ população". Tal é o caso do Crime Organizado - tema sempre atual no Brasil. Ao que se somam as disputas pela verdade narrativa dos fatos e, consequentemente, pelo poder (presente nas palavras) de denominar, classificar, hierarquizar as coisas.

Com referência ao anteparo filosófico, a princípio, o autor mais significativo nos parece ser Raffestin, com seu "Por uma Geografia do Poder". Sua elaboração, em que Território e Poder pressupõem-se mutuamente, é exatamente aquilo que nos permite "geograficizar" a temática, conforme se depreende da citação:

1. O poder não se adquire; é exercido a partir de inumeráveis pontos; 2 . As relações de poder não estão em posição de exterioridade no que diz respeito a outros tipos de relações (econômicas, sociais etc), mas são imanentes a elas; 3. O poder vem de baixo; não há uma oposição binária e global entre dominador e dominados; 4. As relações de poder são, concomitantemente, intencionais e não subjetivas. (Raffestin, 1993, p. 53)

Entenda-se o Poder como uma gama de relações sociais, campos de força, dos quais as cristalizações - representadas pelas instituições sociais são constituídas: "[...] The integrating factors or agents of stratification make up institutions: not just the State, but also the Family, Religion, Production, 
the Marketplace, Art itself, Morality, and so on. [...]"(Deleuze, 1988, p. 75)9. Ao contrário daquilo em que o senso comum acredita, ou seja, que as instituições vêm antes das relações e, portanto, o Poder derivaria delas.

Então, nosso entendimento sobre a territorialização assume a postura segundo a qual Poder e Território pressupõem-se, postura essa encampada pelo francês Raffestin (1993). Para esse autor, é necessário que haja uma "intenção" (liame entre sujeito e objeto) e que essa intenção se desdobre na concretização de um projeto (no Espaço), a partir do qual o comportamento humano deva se pautar. A propósito, Sack não se distancia muito desta concepção. A diferença, quer nos parecer, reside em que Sack (1986) entende a territorialidade como uma estratégia de controle de uma área sob domínio.

Além de Raffestin, do ponto de vista teórico, mas também, agora, metodológico, são fundamentais os autores (com suas respectivas obras) tanto do Culturalismo ${ }^{10}$ quanto do Marxismo ${ }^{11}$. Quando não estiverem, ambas as linhas, presentes numa mesma obra - tal é o caso de Raymond Williams. Num certo sentido, o primeiro (Culturalismo) é um desdobramento pontual do segundo, desdobramento encampado por autores marxistas já descrentes do potencial explicativo de um determinado marxismo (aquele, por exemplo, de Lênin e de Lukács) e, portanto, não existe nenhuma contradição nessa postura de síntese, diante das duas linhas teóricas.

Especificamente na Geografia, a influência dos Estudos Culturais encontra em Paul Claval um dos maiores expoentes. Segundo o autor, que indica como marco cronológico a década de 1970:

O objetivo da abordagem cultural é entender a experiência dos homens no meio ambiente e social, compreender a significação que estes impõem ao meio ambiente, e o sentido dado às suas vidas. A abordagem cultural integra as representações mentais e as reações subjetivas no campo da pesquisa geográfica. (Claval, 2013, p. 93)

9 Os fatores de integração ou agentes de estratificação constituem instituições: não meramente o Estado, mas também a Família, a Religião, a Produção, o Mercado, a própria Arte, a Moralidade e assim por diante. (tradução nossa)

10 Em relação ao dito Culturalismo, me refiro àquela corrente que, originando-se nas Ciências Sociais, na década de 1950 - e cujos marcos seriam R. Hoggart, com o seu Utilizações da Cultura e R. Williams com Cultura e Sociedade (Hall, 2003, p. 132) - disseminou-se pelas áreas afins, tais como a Geografia e a História.

11 Os autores marxistas pululam na geografia. Manteremos sempre em mente os esforços de Neil Smith (1988), Henri Lefèbvre e David Harvey (2005), mas a nossa referência é sempre o próprio Marx. 
Enfim, existe ao menos mais um filósofo contemporâneo que nos parece essencial. Trata-se de Michel Foucault. Porém, especificamente, naquilo que suas reflexões acerca do conceito de Poder correspondem às nossas necessidades. Por exemplo: “[...] não se pode fazer nem a história dos reis nem a história dos povos, mas a história daquilo que constitui, um em face do outro, esses dois termos, dos quais um nunca é infinito e o outro nunca é zero" (Foucault, 1999, p. 200). Nosso ponto de partida, a ideia de que o Poder é ubíquo, de que é inextricável das relações sociais e, portanto, da territorialidade - "[...] é impossível manter uma relação que não seja marcada por ele" (Raffestin, 1993, p. 159) - e de que ele (Poder) não é uma "propriedade" das classes dominantes e nem mesmo da sociedade política, apresenta-se frequentemente na obra de Foucault.

Poder - é claro - que se desdobra quer num politico, num econômico, num simbólico etc. O que buscamos destacar são essas "redes" - que se estabelecem das pessoas entre si mesmas; ou entre objetos técnicos e as pessoas; ou delas com lugares - sem as quais retornaríamos ao que disse La Blache, sobre a geografia não ser a ciência dos homens, mas dos lugares.

\section{Características gerais}

As hipóteses que encampamos são tão variadas quanto o arcabouço teórico. De qualquer forma, quer nos parecer que uma primeira consequência da análise desses territórios marginais por meio do aporte aqui encampado será uma explicação do urbano enquanto um espaço de disputa. Explicação essa que se fundamente, dialogicamente, quer numa descrição dos processos sócio econômicos envolvidos no assentamento das populações fragilizadas em áreas irregulares, quer na interpretação das ações e dos valores incorporados por essas mesmas populações; ações e valores que imprimem uma estrutura e uma dinâmica próprias a esses movimentos de ocupação (das áreas irregulares). Gottdiener (1993, p. 199) utiliza a expressão "dialética entre estrutura e ação" - o que preferimos evitar. Posto que é muito sensível, nas ciências sociais, essa dicotomia que dispõe uma estrutura (framework), frequentemente a-escalar e invariavelmente determinista, à ação social dos sujeitos.

Assim, no bojo da territorialização - enquanto processo social inerente - encontramos, envolvidos, grupos diversos guiados por interesses distintos: empresas de incorporação imobiliária, instituições públicas, pessoas físicas etc. uns movidos pelo lucro, outros pela necessidade de 
habitação. Sendo que a importância (e, portanto, a efetivação) desses interesses constitui-se em si mesmo num elemento de natureza política, que amplia a complexidade de nosso desafio. Justamente essa "ordem de importância" resultará em territórios privilegiados - em linhas gerais, os espaços luminosos de Milton Santos (1997) - e, no outro extremo, em espaços opacos (ibidem), à margem dos quais encontramos os territórios marginais; privados, muitas vezes, até mesmo de existência ${ }^{12}$.

Além disso, dessa mesma análise se depreende um enriquecimento da perspectiva teórica denominada: Produção do Espaço ${ }^{13}$. Uma vez que a marginalização - esse processo top-down - é ao mesmo tempo bottom-up, no que se refere aos seus modos de territorialização. Ora. Paugan (2003) já alerta para a resistência das populações empobrecidas face à tutela do estado. A fortiori, o estabelecimento das relações sociais inerentes ao processo de territorialização nos conduz justamente ao reconhecimento de uma autopoiese. Nesse sentido, a marginalidade resultante da ordem de importância dos interesses das populações empobrecidas - ou melhor, da sua "desimportância" - não interfere (supomos) no vigor das mesmas relações sociais e, portanto, em sua territorialidade.

Então, se faz necessário compreendermos tanto a territorialidade quanto a reticularidade desses espaços. Claro que isso não se faz cartograficamente, mas deslindando as reciprocidades entre os sujeitos, ou melhor, as "relações de poder" que configuram o território. Com isso, os chamados "aglomerados de exclusão" podem ser portadores de táticas de inclusão, na medida em que os sujeitos marginalizados, habitantes e produtores desses espaços que a sociedade preferiria esquecer, são capazes de estabelecer ligações entre si e com a sociedade como um todo.

A experiência contemporânea do Ejército Zapatista de Liberación $\mathrm{Na}$ cional (EZLN) com a utilização da internet em sua guerra de palavras contra o governo mexicano (Bisco Júnior, 2007), mesmo isolado na selva de Lacandona, em Chiapas, serve como índice das potencialidades do uso das tecnologias contra a estrutura produtiva que as forjou. Mas, não estamos (ainda) de posse de nenhuma evidência indicando que esse mesmo recurso seja utilizado pelas populações que analisamos. Em todo caso, voltaremos a isso adiante.

12 Diversos são, atualmente, no Brasil, os programas de "desfavelização" que, como o nome já diz, visam eliminar as favelas e transferir suas populações para habitações populares.

13 Na acepção em que seu precursor, Lefebvre, empresta à mesma perspectiva (Gottdiener, 1993, p. 127-135). 
Com relação à reticularidade, partimos da definição inicial de Gerald Pitzl (2004, p. 156) até chegarmos a Manuel Castells (2001) com a noção de "espaço de fluxos". Evidentemente, a Rede (no caso, urbana) está associada aos "espaços velozes", sobretudo das cidades globais. Nesse sentido, pensamos em averiguar se é possível falarmos (ou não) em Rede quando a referência é o hinterland: os espaços considerados "entre-nodais". A analogia que nos convida a aventar essa hipótese é fornecida pelos estudos de Geografia Política:

Trabalhando nas bases fornecidas por Max Weber, sociólogos (como Amitai ETZIONI, 1964; 1968), antropólogos (como Jacques MAQUET, 1970) e geógrafos (como Paul CLAVAL, 1978) têm explorado os métodos de como estas formas de poder são incorporadas em sistemas institucionalizados de relações sociais, que caracterizam sociedades. Eles enfatizam o papel da família (em suas dimensões de descendência e aliança), associações, mercados, relações pedagógicas, relações de mestre/escravo, tirania, casta, relações feudais, relações burocráticas, relações de poder-autoridade. Alguns padrões são igualitários, outros hierárquicos. Esta análise é importante, pois mostra que a vida política pode estar ativa em sociedades onde não há instituições políticas especializadas, como em tribos sem regras descritas por alguns antropólogos que são, muitas vezes, "sociedades contra o Estado", como Pierre Clastres cita. (Claval, 2013, p. 75)

A propósito, essa articulação entre territorialidade e reticularidade pressupõe que adotemos diferentes escalas ${ }^{14}$. De modo que, tanto no que se refere ao espaço urbano enquanto produção social, quanto no que tange à diferenciação-seletividade intra-urbana - com a consequente desigualdade sócio espacial - buscamos esboçar (evitando dizer: definir) esse "sistema de objetos e de ações" (Santos, 2002, p. 63) em que constitui-se o referido território marginal.

14 Cada qual, tomada em sua própria geografia: "Processes of scalar structuration do not produce a single nested scalar hierarchy, an absolute pyramid of neatly interlocking scales, but are better understood as a mosaic of unevenly superimposed and densely interlayered scalar geometries. For, as Allen, Massey and Cochrane (1998: 60 ) indicate, . . . different kinds of social process have very different geographies and they do not all fit neatly into the same set of nested hierarchies (see also Lefebvre, 1991 [1974]: 85-88)" (Brenner, 2001, p. 606).

Processos de estruturação escalar não produzem uma hierarquia escalar única e de formato aninhado, uma pirâmide absoluta de escalas ordenadamente bloqueadas, mas são melhor compreendidos como um mosaico de geometrias escalares desigualmente sobrepostas e densamente intercaladas. Pois, como Allen, Massey e Cochrane nos indicam, ... . diferentes tipos de processo social têm geografias muito diferentes e nem todas se encaixam perfeitamente no mesmo conjunto de hierarquias aninhadas (ver também Lefebvre). (tradução nossa ) 
Elias Coimbra Da Silva. Reflections on the territorialization of the poverty in brazilian cities

\section{Metodologia}

A nossa pesquisa compõe-se de uma coleta de informações, na qual os lugares serão identificados segundo procedimentos como: 1- levantamento de fontes impressas (através da própria internet, inicialmente); 2- observação da cartografia (aquela contida em Melazzo, 2006, por exemplo) e de imagens contidas em sítios (raster, fotografia aérea etc.) da internet, nas quais as construções irregulares demonstram padrões diferentes; 3- trabalho de campo. Observando que o trabalho de campo apresenta-se como a situação mais propícia à construção de evidência oral.

Paralelamente, procedemos à consulta bibliográfica referente ao tema. Autores como Paugan, Haesbaert, Rocha, Melazzo, enfim, quaisquer textos que versem acerca da Exclusão Social, ou ideias afins, serão tomados em conta e a leitura dos mesmos fundamentará nossa argumentação. Da mesma forma, os autores que oferecerem suporte teórico, como Raffestin, Castells e Lefebvre, instrumentalizando nossa pesquisa, respectivamente através de conceitos como Território, Rede, Urbano etc. serão consultados e as suas ideias nos serão de grande importância.

$\mathrm{Na}$ sequência utilizamos a análise e/ou à interpretação das informações; conforme a natureza da fonte. No caso, em se tratando de informações cujo significado seja basicamente descritivo, procederemos àquilo que se poderia tomar por "análise", no sentido em que Kant (entre outros) empresta ao termo, ou seja, em "proposições cujo predicado faz parte do sujeito" (Russell, 1967, p. 248). Por outro lado, quando as informações envolverem representações, valores, sentimentos etc., procederemos à interpretação.

Destacamos, oportunamente, que toda e qualquer fonte é portadora de significações tanto objetivas quanto subjetivas. Além do que, no bojo da própria objetividade coexistem informações explícitas e implícitas (essas veladas com ou sem algum propósito). As fontes verbais demonstram isso com maior frequência, de forma que a nossa experiência junto da metodologia da Crítica das Fontes, tipicamente utilizada na pesquisa em História, será inevitavelmente mobilizada.

Foi assim que nos deparamos com algumas das fontes até o momento. A mesma mediação estabelecida entre o sujeito e a realidade, através das Representações, e encontrada pelo historiador quando esse está diante do passado (Fico, 2000, p. 42), nos foi absolutamente visível em diversos momentos. Sintomática é a divergência em torno do termo "favela": como o poder público 
mantem a continuidade entre o histórico desse termo e uma posição (uma autoridade) frente à opinião pública é algo completamente diferente da referência - inconstante - que as pessoas que convivem (com, e) nesses espaços fazem à "favela"; palavra que pode ser permutada por "comunidade".

O que falta - com certeza na Geografia, embora muito menos na História - é alçar esses sujeitos, hoje à margem, a uma condição de protagonismo. Nesse caso, a minha formação enquanto historiador me conduz espontaneamente nessa direção, bem como torna inevitável a referência ao Edward P. Thompson; sobretudo naquilo que ele definiu como história vista de baixo; tal como nessa passagem

Certa vez, em um entrevista nos Estados Unidos perguntaram a E. P. Thompson qual sua opinião sobre a historiografia inglesa. E ele respondeu mais ou menos assim: Creio que grande parte da historiografia, principalmente na Inglaterra, considerou a sociedade do ponto de vista das expectativas e da auto-imagem da classe dominante: a propaganda dos vencedores. Por isso, eu creio que recuperar uma história alternativa supõe quase sempre polemizar com a ideologia dominante. (Thompson, 1987)

Trata-se de uma proposta tanto teórica quanto metodológica, na medida em que pesquisas com populações empobrecidas são muito frequentes - nas quais, porém, elas são objetos e não sujeitos. O próprio Instituto Brasileiro de Geografia e Estatística (IBGE) - responsável por boa parte das informações das quais dispomos (aliás, com facilidade) - realiza constantemente pesquisas; mesmo que metodologicamente restritivas (quando baseiam-se apenas em Questionários Fechados).

Estando o trabalho com as fontes completo, nos restará produzir o texto da tese. Texto esse de caráter discursivo-explicativo, no qual a presença de cartografia ocupará uma posição apenas ilustrativa. Do mesmo modo, não propomos nenhum prognóstico ou método de intervenção na realidade. Portanto, não sendo uma pesquisa apenas bibliográfica, ainda assim, nossa proposta limita-se ao entendimento dum recorte da realidade.

\section{Área de estudo}

O conceito de Território Marginal, aqui adotado, dialoga com a noção de institucionalização da pobreza, desenvolvida por Paugan (apud 
Melazzo, 2006, p. 53): “[...] explicita-se o recorte da análise quando afirma que seu objeto não é a pobreza, mas as formas institucionais que esta assume". Aliás, não é absoluta a diferença entre essa noção e a "modernização da pobreza", apontada por Ivan Illich ${ }^{15}$. Muito pelo contrário. Ambos os autores tratam do mesmo problema, embora o viés de Illich seja consideravelmente mais político do que apenas econômico.

Outrossim, destacamos que para além da questão sociológica e, $a$ fortiori, econômica, a pobreza também assume uma forma geográfica; uma territorialidade. Não são outra coisa as chamadas favelas, do que "territórios", cuja cristalização de relações de poder - Poder no sentido aqui indicado, anteriormente - pressupõe e, dialeticamente reproduz, grupos humanos.

De qualquer forma, a presença de áreas nas cidades brasileiras com características de ocupações irregulares ou "favelas" - termo esse, atualmente, substituído por "comunidade", em função do sentido pejorativo por ele evocado (Freire, 2008) - se mostra progressivamente maior. Nesse sentido, consideramos premente a necessidade de compreendê-las e não enquanto continuidade daqueles espaços (ou "aglomerados"16) de exclusão, mas naquilo que elas, as áreas de ocupação irregular, representam em si mesmas. Evidentemente, a "comunidade" representa alguma (outra) coisa para os outsiders - nesse caso, representa a "favela" (o pejorativo). $\mathrm{O}$ que nos leva à realidade aqui estudada.

Quanto ao nosso recorte espacial, o estudo - do qual deriva este artigo - centra-se na cidade de Ribeirão Preto, Estado de São Paulo. Segundo o Instituto Brasileiro de Geografia e Estatística (2016) esse é um município de 674.000 habitantes, localizado a 316 quilômetros a nor-noroeste de São Paulo - cidade e capital - e com R\$42.682,00 de PIB per capita, $\equiv$ US\$ $13.110,00$.

\footnotetext{
15 "Departamentos de bem-estar reivindicam um mono-pólio profissional, político e financeiro sobre a imaginação social, estabelecendo padrões para o que é proveitoso e o que é possível. Este monopólio está na raiz da modernização da pobreza. Qualquer simples necessidade, para a qual foi encontrada resposta institucional, permite a invenção de nova classe de pobres [...].” $(1985$, p. 17)

16 O termo é utilizado por Haesbaert (1995).
} 
Figura 1. Fotografia aérea com a localização (polígono tracejado) da "Favela Avenida Rio Pardo". Data: 13 abr. 2016. Coordenadas (ponto hipotético no centro): $21^{\circ} 09^{\prime} 09^{\prime}$ 'S, $47^{\circ} 50^{\prime} 07^{\prime \prime} \mathrm{W}$

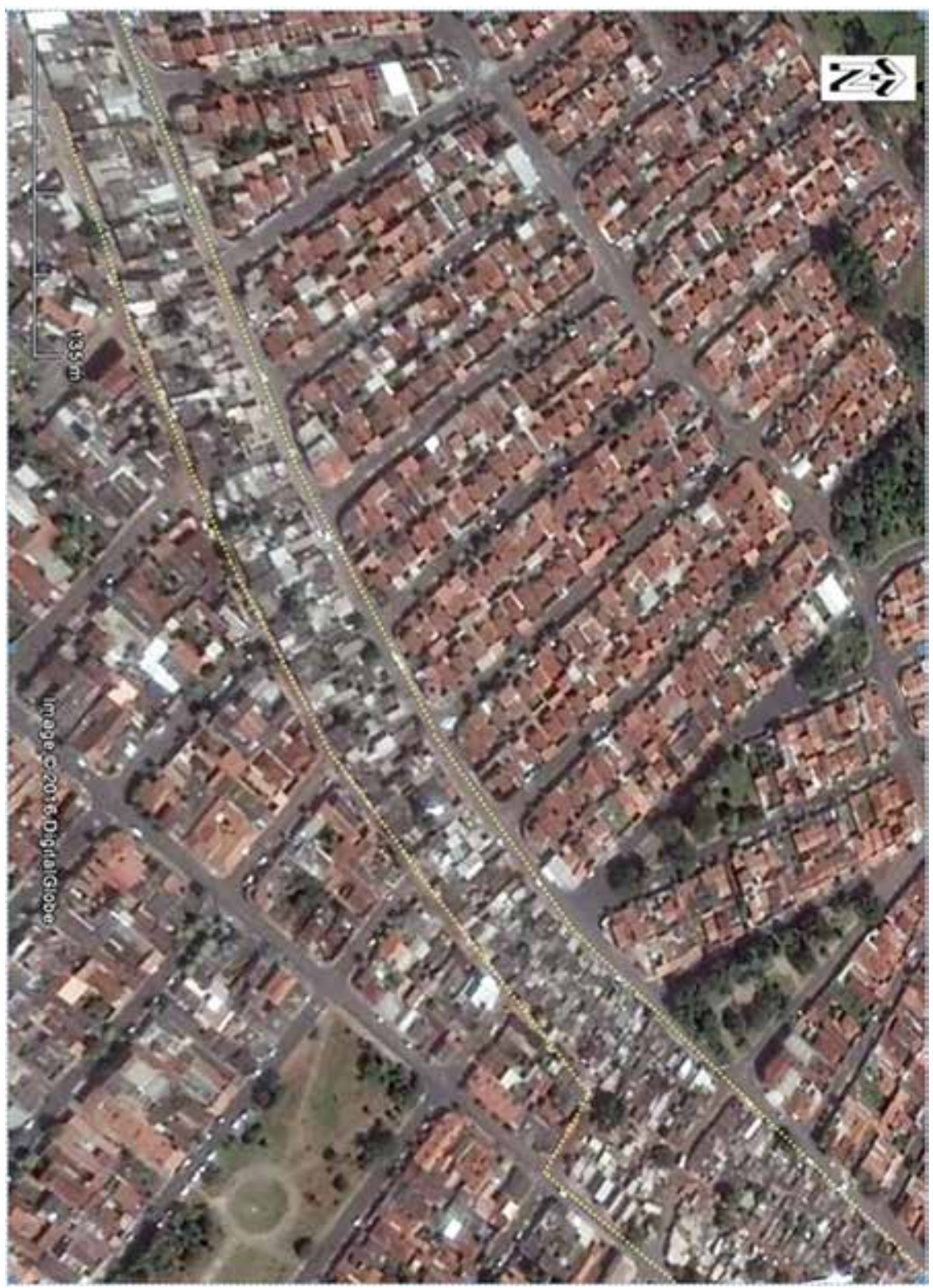

Fonte: Google Earth, 2016. Edição do autor 
No chamado Setor Oeste dessa cidade média paulista, no Bairro Ipiranga, encontramos um cinturão de pouco mais que 01 quilômetro de comprimento e não mais que 50 metros de largura, composto por habitações irregulares que foram sendo construídas sobre onde havia (anteriormente) a linha férrea da FCA (Figura 1); e ao longo da última década. Tal cinturão, conhecido localmente como "Favela da Avenida Rio Pardo" (ou Favela do Trilho), constitui aquilo que denominamos: Território Marginal. Para sermos mais precisos, a ocupação tem $27.936 \mathrm{~m}^{2}$, com 238 unidades e 1.188 habitantes - no levantamento realizado em 2010 (Ribeirão Preto, 2010, p. 42).

Como esperado, temos verificado a construção (discursiva) unânime de uma favela (da Avenida Rio Pardo) enquanto território marginal. No âmbito das práticas, os atores sociais "de fora" (outsiders) buscam a caracterização de uma marginalidade com intuito claro de saná-la (a sua Endlösung ${ }^{17}$ ). Apesar de não existir uma politica pública municipal visando remover essa favela de sobre os trilhos da antiga linha, é útil estabelecermos uma analogia demonstrando como, esse poder público local, lida com a "questão das favelas".

No sítio eletrônico da Prefeitura Municipal de Ribeirão Preto encontramos um tópico intitulado: "Projeto para urbanização da Favela Via Norte". Abaixo encontramos o documento: "Concepção de Projeto - Área 1 Assentamento Precário Via Norte". Trata-se de um volume com 77 páginas, sendo 26 delas dedicadas à questão ambiental (no sentido ecológico mesmo), mais 22 páginas para a questão fundiária (sempre pautada em legislação) e, finalmente, encontramos 7 páginas (65-72) dedicadas às pessoas que moram no local. Mas, observemos um pouco melhor. A partir da página 67, lê-se: "Planejamento e diagnóstico social":

A equipe técnica envolvida se reúne com a equipe da Prefeitura para traçar um diagnóstico preliminar da situação. O diagnóstico social deve ser elaborado a partir de estudos específicos abarcando aspectos socioeconômicos, organizativos e de território, sempre em consonância com as análises físicas, urbanísticas, jurídicas e ambientais. Tais informações relacionadas permitem o alcance de uma compreensão que foge do senso comum e sintetiza uma situação e contexto, [...]. Em concomitância, a leitura da

17 "Solução Final", ou seja, a última prática adotada pelos nazistas no sentido de solucionar o problema em que os judeus constituíam-se. É desnecessário dizer que a solução foi o extermínio. 
realidade deve considerar as dinâmicas presentes no território, as disputas, conflitos, grupos de interesses, cultura local, histórico de formação e, sobretudo, o entendimento que seus moradores tem da realidade, seus anseios, necessidades, proposições e desejos (Viecili, 2015). [grifo nosso]

Curiosa essa coexistência de um condicionante êmico: "o entendimento que seus moradores tem da realidade" com a proposição tecnocrática: "uma compreensão que foge do senso comum". Fato que se explica melhor quando descobrimos que o autor do projeto é um engenheiro florestal: Leandro Galhardo Viecili, CREA-SP n.5061514374. Essa é, portanto, a postura do ente público no trato com a "questão das favelas". Quer nos parecer muito mais a concepção e lida com um ecótopo do que com uma "sociação" - esse último conceito é de Georg Simmel. 
Elias Coimbra Da Silva. Reflections on the territorialization of the poverty in brazilian cities

Figura 2. Planta de Ribeirão Preto, onde vemos a "Favela Avenida Rio Pardo

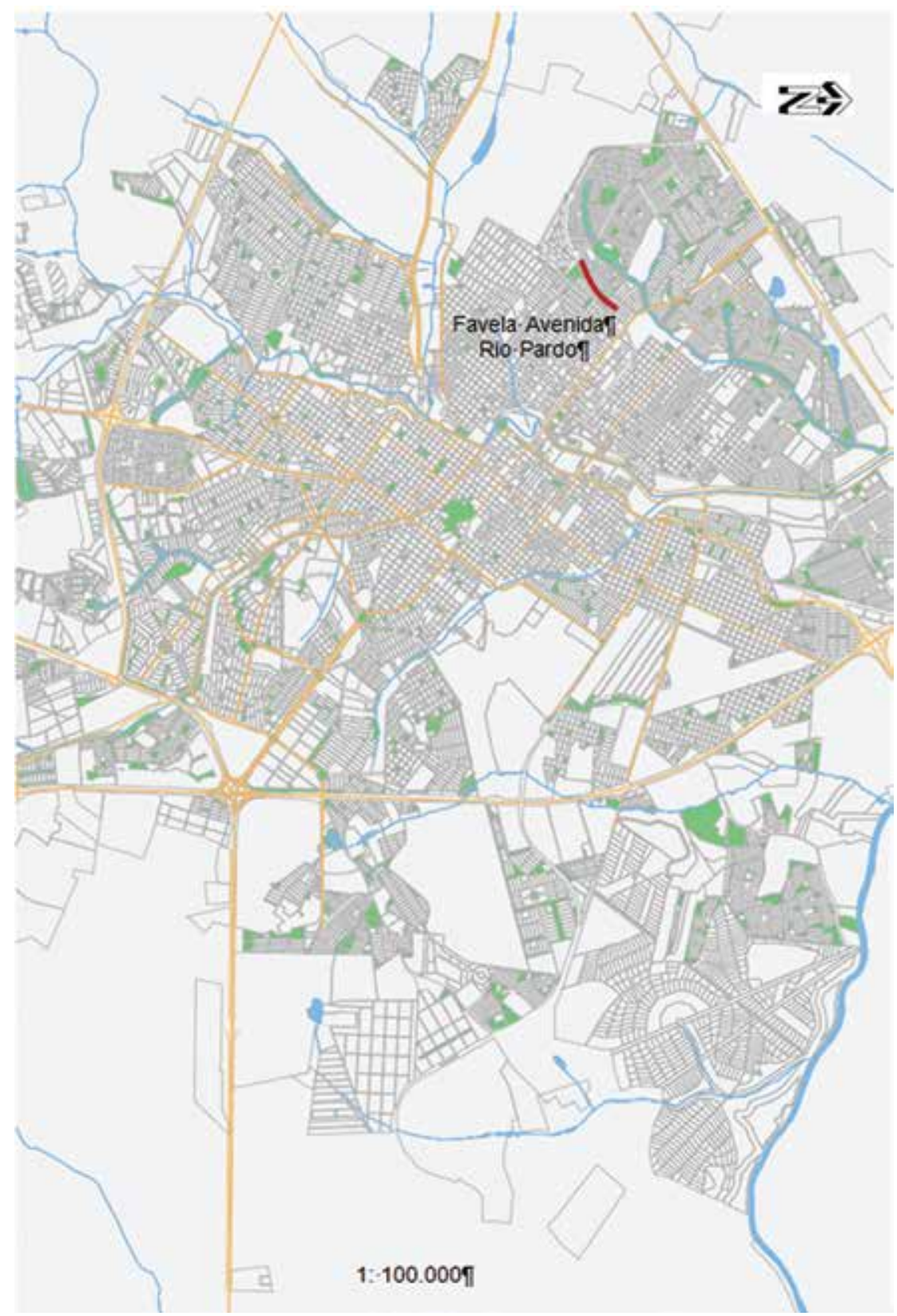

Fonte: Prefeitura Municipal de Ribeirão Preto, 2017.

Disponível em: $<$ http://www.ribeiraopreto.sp.gov.br 
Do ponto de vista de alguns dos moradores do Bairro Ipiranga (porém outsiders com relação à Comunidade do Trilho), a "marginalidade" pode ser verificada até mesmo na inadequação ao hábito correto de habitação: "As pessoas ganharam casa do Minha Casa Minha Vida ${ }^{18}$ e voltaram para morar na favela [da Avenida Rio Pardo]. Deixaram a casa lá, bonitinha, e voltaram pra favela" (Silva, 2017). No que podemos considerar variadas hipóteses: (1) os laços com o território são fortes o bastante para reter o morador na favela; (2) o morador não conseguiu honrar o financiamento; etc.

Seja qual for a explicação, o fato é que a resistência das populações vizinhas (da Comunidade da Av. Rio Pardo) à presença desse grupo, apenas atesta as disputas inerentes ao processo de territorialização (disputa por espaço, por visibilidade, entre outras coisas).

\section{Resultados esperados}

O trabalho resultante de nossa pesquisa - na qual o presente artigo cumpre uma etapa - não se utilizará de séries estatísticas nem buscará auferir a quantidade ou a intensidade dos fenômenos. Ainda assim, o texto e produto final, não é um ponto de chegada, mas um processo de aproximação ao tema eleito. Isso implica num dever de explicitarmos, sempre que necessário, as nossas fontes, indicando quem as produziu, como, quando e por qual motivo. No mesmo sentido, não silenciaremos acerca do "lugar de onde falamos" 19 expondo nossos julgamentos acerca das operações produzidas por nós mesmos e as motivações que lhes dão anteparo.

Pois, não existe algo como neutralidade ou - como prefeririam os estruturalistas - não existiria relação translúcida entre o sujeito que pensa e o mundo que é pensado. Isso ficou patente acima, na breve análise do projeto acerca do "Assentamento Precário Via Norte". Da mesma forma que fica patente na metodologia dos Questionários Fechados que busca

18 O programa "Minha Casa Minha Vida" é uma política pública federal cujo objetivo é o financiamento de imóveis populares. No Bairro Ipiranga, onde a Favela Av. Rio Pardo localiza-se, existem 448 residências relacionadas a esse programa (Ribeirão Preto, 2010, p. 48)

19 Michel de Certeau assim expressa essa dificuldade: “[...] Encarar a história como uma operação será tentar, de maneira necessariamente limitada, compreendê-la como a relação entre um lugar (um recrutamento, um meio, uma profissão, etc.), procedimentos de análise (uma disciplina) e a construção de um texto (uma literatura). É admitir que ela faz parte da realidade da qual trata, e que essa realidade pode ser apropriada enquanto atividade humana, enquanto prática. Nesta perspectiva, gostaria de mostrar que a operação histórica se refere à combinação de um lugar social, de práticas científicas e de uma escrita. Essa análise das premissas, das quais o discurso não fala, permitirá dar contornos precisos às leis silenciosas que organizam o espaço produzido como texto [...]". (1982, p. 66) 
falar em nome das pessoas - ali, na pesquisa, onde elas se encontram logicamente ausentes - mas, que apenas encaixam-nas dentro de categorias pré-estabelecidas: sexo, idade, renda etc.

Por outro lado, a natureza do recorte nos impõe um horizonte de conhecimento limitado - no sentido de um domínio pleno do tema: o território marginal. Isso significa dizer que trata-se dum estudo idiográfico. Todavia, não nos filiamos diretamente à geografia regional. Trata-se antes de realizar um trabalho de "descrição densa", ou seja, conhecer o que quer que procuremos conhecer, além de minuciosamente, também nos próprios termos, ou seja, o fenômeno não precisa ser exemplar, com relação a leis ou padrões que não reconhecem fronteiras, mas sim, ele apresenta-se significativamente dentro da escala considerada; como explica Paul Claval (2013, p. 94):

A realidade que os geógrafos estudam é sempre aquela de uma cultura particular. Como analisar essa realidade sem considerar seus recortes mais importantes, sem perder o que faz a sua especificidade? Ao desconfiar dos relatórios simples, por serem feitos na ótica do observador, o etnólogo Clifford Geertz nos dá um norte. O etnólogo e o geógrafo devem praticar a arte da 'descrição densa' (thick description).

Nesse sentido, não há que se falar em uma busca de leis gerais, aplicáveis a quaisquer fenômenos análogos, mas - repetimos - do aprofundamento acerca de um fenômeno pontual, aprofundamento esse cuja a função lançaria uma luz diferenciada sobre um problema já estudado. Fato que nos aproxima, de alguma forma, da perspectiva (mais prática do que teórica) conhecida como Micro-história (Revel, 2000, p. 18), a qual não toma em conta apenas as normas e estruturas sociais, mas, sobretudo, as estratégias de utilização das mesmas pelos sujeitos. Proposição que vai ao encontro do conceito de Território (aqui utilizado) com suas redes de reciprocidades.

Esse é um recurso que permite apontar nuanças ou até mesmo erros nas chamadas leis gerais. Assim, partimos do singular, em direção a certas verdades estabelecidas concluindo, eventualmente, pela imprecisão das mesmas verdades. Nessa perspectiva teórica, o ponto de chegada é o "geral" (de novo), mas entre aspas mesmo, posto ser, então, o geral somado ao detalhamento que o tensiona. 
A "favela", por exemplo, mais do que uma definição é um significado em disputa e não se trata apenas da pobreza ou da marginalização. A favela envolve também um espaço construído; e envolve um Território. Por si só, esse aporte geográfico já estabelece uma tensão no interior da abstração: "favela". Junte-se a isso as especificidades da Favela Av. Rio Pardo, com as relações sociais que lhe são próprias, com as circunstancias próprias de seu assentamento (a linha do trem) e conseguiremos deslindar a complexidade que muitas vezes um conceito encobre.

Last but not least, reforçamos que o Território não é nosso ponto de partida - papel que cabe ao nosso recorte - mas, um ponto de chegada e que sua importância apenas começa a ser observada. Aliás, observada não apenas na geografia (antropólogos e sociólogos também vêm se utilizando desse conceito). A partir dele, acreditamos ser possível enxergar a forma como os sujeitos se apropriam do espaço, enquanto estabelecem as relações sociais que cimentam a existência do grupo. Por outro lado, entendemos que um grupo que se opõe às normas e que, nesse caso, apropria-se de um terreno que o imperativo da Propriedade Privada torna defeso, constitui-se (inclusive no plano simbólico) enquanto essa "marginalidade" que os grupos submissos às normas atribuem.

Entretanto - e como temos já identificado - o que move as pessoas à marginalidade é a própria norma, posto que o acesso à terra urbana é extremamente seletivo em cidades como Ribeirão Preto: onde um imóvel com $100 \mathrm{~m}^{2}$ de construção pode custar até 510 salários mínimos (Viva Real, 2016). De modo que essa população vê-se como sujeito de todos aqueles direitos experimentados pelos grupos submissos (às normas). Nesse momento, a disputa acerca da narrativa dos fatos nos impõe a necessidade de adotarmos aquela noção de Poder; e então, percebemos que isto sobre o qual estamos pisando se chama Território.

\section{Referências}

Barth, F. (1981). "Anthropological models and social reality". Process and form in social life. London/Boston/Henley-on-Thames, U.S.A./ U.K.: Routledge \& Kegan Paul. (pp. 14-32)

Bisco Júnior, J. V. (2007). Guerrilha em foco: a presença na mídia do discurso Zapatista, de seu surgimento até a Quinta Declaração da Selva 
Lacandona. Dissertação de mestrado. Instituto de Ciências Humanas

e Sociais, Universidade Federal de Ouro Preto. Brasil. (pp. 139)

Bourdieu, P. (1998). O Poder Simbólico. Tradução Fernando Tomaz. 2. ed.

Rio de Janeiro, Brasil: Bertrand Brasil.

Brenner, N. (2001). The limits to scale? Methodological reflections on sca-

lar structuration. In: Progress in Human Geography, 25(4), 591- 614.

Castells, M. (2001). A sociedade em rede. Tradução Roneide Venancio Majer. 8ed. São Paulo, Brasil: Paz e Terra.

Cavalcanti, L. P. (2006). Moderno e brasileiro: a história de uma nova linguagem na arquitetura (1930-1960). Rio de Janeiro, Brasil: Jorge Zahar.

Claval, P. (2013). "Por Paul Claval”. Almeida, M. G.; Arrais, T. A. (Org.). É geografia, é Paul Claval. Goiânia, Brasil: FUNAPE. (pp. 74-176)

Cosson, R. (2005). "Romance-reportagem: o império contaminado". Castro, G; Galeno, A. (Org.). Jornalismo e literatura: a sedução da palavra. 2. ed. São Paulo, Brasil: Escrituras Editora. (pp. 57-70)

De Certeau, M. (1982). A Escrita da história. Tradução Maria de Lourdes Menezes. Rio de Janeiro, Brasil: Forense Universitária.

Deleuze, G. (1988). Foucault. Translated and edited by Sean Hand. Minneapolis, United States: University of Minnesota Press.

Deleuze, G.; Guattari, F. (1995/a). Mil platôs: capitalismo e esquizofrenia. Vol. 1. Tradução Aurélio Guerra Neto e Célia Pinto Costa. Rio de Janeiro, Brasil: Ed. 34.

Deleuze, G.; Guattari, F. (1995/b). Mil Platôs: capitalismo e esquizofrenia.

Vol. 2. Tradução Ana Lúcia de Oliveira e Lúcia Cláudia Leão. São Paulo, Brasil: Ed. 34.

Fico, C. (2000). "Algumas anotações sobre historiografia, teoria e método no Brasil". Guazzelli, C. A. B. et al. (org.). Questões de Teoria e Metodologia da História. Porto Alegre, Brasil: Ed. Universidade/ UFRGS. (pp. 27-40)

Foucault, M. (1999). Em defesa da sociedade - curso no Collège de France (1975-1976). Tradução Maria Ermantina Galvão. São Paulo, Brasil: Martins Fontes.

Freire, L. L. (2008). Favela, bairro ou comunidade? Quando uma política urbana torna-se uma política de significados. In: Dilemas: revista de estudos de conflito e controle social,1(2), 95-114. 
Gottdiener, M. (1993). A Produção Social do Espaço Urbano. Tradução Geraldo Gerson de Souza. São Paulo, Brasil: EDUSP.

Haesbaert, R. (1995). "Desterritorialização: entre as redes e os aglomerados de exclusão". Castro, I. et al. (Org.). Geografia: conceitos e temas. Rio de Janeiro, Brasil: Bertrand Brasil. (pp. 165-206)

Haesbaert, R. (2006). O Mito da Desterritorialização. 2. ed. Rio de Janeiro, Brasil: Bertrand Brasil.

Hall, S. (2003). Da diáspora: identidades e mediações culturais. Tradução Adelaine La Guardia Resende et al. Belo Horizonte/Brasília, Brasil: Editora UFMG/Representação da UNESCO no Brasil.

Harvey, D. (2005). A produção capitalista do espaço. Tradução Carlos Szlak. São Paulo, Brasil: Annablume.

Illich, I. (1985). Sociedade sem escolas. Tradução Lúcia M. Endlich Orth. 7. ed. Petrópolis, Brasil: Vozes.

Instituto Brasileiro de Geografia e Estatística. (2016). Cidades@, IBGE. Disponível em: http://cidades.ibge.gov.br/xtras/perfil. php?lang=\&codmun $=354340 \&$ search $=$ sao-paulo|ribeirao-preto.

Lefebvre, H. (1999). A revolução urbana. Tradução Sérgio Martins. Belo Horizonte, Brasil: Editora UFMG.

Melazzo, E. S. (2006). Padrões de desigualdades em cidades paulistas de porte médio. A agenda das políticas públicas em disputa. Tese de doutorado. Faculdade de Ciências e Tecnologia, Universidade Estadual Paulista. Brasil. (pp. 230)

Paugam, S. (2003). A desqualificação social: ensaio sobre a nova pobreza. Tradução Renata Dias de Carvalho. Porto, Portugal: Porto Editora.

Pitzl, G. R. (2004). Encyclopedia of Human Geography. Westport/London, U.S.A./U.K.: Greenwood Press.

Portelli, A. (1996). A Filosofia e os Fatos: narração, interpretação e significado nas memórias e nas fontes orais. In: Tempo, Vol.1, $\mathrm{N}^{\circ} 2$. (pp. 59-72)

Raffestin, C. (1993). Por uma Geografia do Poder. Tradução Maria Cecília França. São Paulo, Brasil: Ática.

Revel, J. (2000). “A história ao rés-do-chão: prefácio”. Levi, G. A herança imaterial: trajetória de um exorcista no Piemonte do séc. XVII. Tradução Cynthia M. Oliveira. Rio de Janeiro, Brasil: Civilização Brasileira. (pp. 07-36) 
Ribeirão Preto. Conselho Municipal de Moradia Popular. (2010). Plano de habitação de interesse social de Ribeirão Preto/SP. Disponível em: http:/www.habitacao.sp.gov.br/secretariahabitacao/downloads/ pehsp/5_encontro_regional_ribeirao_preto_out10_19_2010/municipios_expositores/out19_2010_plhis_ribeirao_preto.pdf

Rolnik, R. (1997). A cidade e lei: legislação, política urbana e territórios na cidade de São Paulo. São Paulo, Brasil: Studio Nobel/FAPESP.

Russell, B. (1967). "Capítulo XX: Kant”. História da Filosofia Ocidental. Tradução Brenno Silveira. 2. ed. São Paulo, Brasil: Companhia Editora Nacional. (pp. 243-261)

Sack, R. (1986). The human territoriality - its theory and history. Cambridge, U.K.: Cambridge University Press.

Santos, M. (2002). A natureza do espaço: técnica e tempo, razão e emoção. São Paulo, Brasil: EDUSP.

Santos, M. (1997). Técnica, espaço e tempo: globalização e meio técnico científico informacional. 3. ed. São Paulo, Brasil: HUCITEC.

Silva, J. S. (2017), 49 anos, moradora do Bairro Ipiranga: depoimento. Entrevista concedida a Elias Coimbra da Silva, em 12 de fevereiro de 2017.

Smith, N. (1988). Desenvolvimento Desigual: natureza, capital e a produção do espaço. Tradução Eduardo de Almeida Navarro. Rio de Janeiro, Brasil: Bertrand Brasil.

Thompson, E. P. (1987). A formação da classe operária. Vol. 1. Tradução Denise Bottman. Rio de Janeiro, Brasil: Paz e Terra.

Viecili, Leandro Galhardo. (2015). Concepção de Projeto - Área 1 Assentamento Precário Via Norte. Ribeirão Preto, 2015. Disponível em: https:// www.ribeiraopreto.sp.gov.br/sccivil/conselho/concepcao_projeto.pdf

Viva Real, Imobiliária. (2016). Casa com 3 quartos à venda, $100 \mathrm{~m}^{2}$ por R\$ 455.000,00. Avenida Heráclito Fontoura Sobral Pinto, 1855, Condomínio Evidence, Ribeirão Preto, SP. Disponível em: https://www.vivareal.com.br/imovel/casa-3-quartos-condominio-evidence-bairros-ribeirao-preto-com-garagem-100m2-venda-RS455000-id-77990741

Williams, R. (2000). "Teoría cultural”. Marxismo y literatura. Traducción de Pablo di Masso. 2. Ed. Barcelona, España: Ediciones Península. (pp. 91-165) 